\title{
Creutzfeldt-Jakob disease, new variant Creutzfeldt-Jakob disease and bovine spongiform encephalopathy - An update
}

$\mathrm{T}$ he recent report of a new variant of Creutzfeldt-Jakob disease (CJD) from the United Kingdom (1) among unusually young patients and with links to bovine spongiform encephalopathy (BSE) prompted this review of developments in this area. Transmissible spongiform encephalopathies (TSE) are rare forms of progressive neurodegenerative disorders that affect both humans and animals (2). Characteristic features include prolonged incubation periods, spongiform changes (microscopically visible vacuoles in the parenchyma of the brain) associated with neuronal loss and a failure to induce inflammatory response (3). Other neuropathological hallmarks include astrocytosis, and occasionally the presence of kuru plaques. TSEs include CJD, variant CJD, kuru, fatal familial insomnia and Gerstmann-Strausler-Scheinker syndrome in humans, and scrapie, mink encephalopathy, BSE, chronic wasting disease of elk, feline spongiform encephalopathy and spongiform encephalopathy of exotic ungulates in various animal species (1,4-8).

The prototype TSE in humans, CJD, has three distinct patterns. It may occur sporadically (approximately $90 \%$ of cases), through autosomal dominant inheritance (approximately 10\% of cases) or through iatrogenic transmission of the infective agent (less than $1 \%$ of cases) $(9,10)$. In iatrogenic cases, person-to-person transmission has been associated with corneal transplants, dura mater grafts, pericardial grafts, peripheral injections of pooled pituitary gland extract (growth hormone injection) and the use of contaminated neurosurgical instruments (11-17). CJD is a rapidly fatal dementing illness that occurs worldwide, with an estimated incidence of approximately one case per million persons in an equal male:female ratio. Although the ingestion of animal brains and a history of surgical procedures have been implicated as putative risk factors, a recent reanalysis of case control studies revealed only two risk factors including a family history of CJD and a history of psychotic illness (18-21).

Increasing evidence suggests that unconventional agents termed prion proteins (PrP), which are encoded by genes on chromosome 20, are considered of central importance in the etiology of CJD. The PrP is a fragment of a normal and ubiquitous protease-sensitive glycoprotein with a molecular weight of 33 to $35 \mathrm{kDa}$. The native protein is designated $\mathrm{PrP}^{\mathrm{c}}$ and the disease-related isoform is designated $\operatorname{PrP}^{S c}(22)$. The latter disease-related isoform $\mathrm{PrP}^{\mathrm{SC}}$ is distinguished from its normal isoform by its insolubility and resistance to proteases. $\mathrm{PrP}^{\mathrm{Sc}}$ is formed from the normal isoform by a post-translational mechanism that involves a distinct conformational modification (23). Several lines of study support a model of $\mathrm{PrP}^{\mathrm{Sc}}$ propagation that involves a direct interaction between the disease-related isoform and the normal isoform, acting to promote conversion of normal $\operatorname{PrP}^{\mathrm{C}}$ to abnormal $\mathrm{PrP}^{\mathrm{Sc}}$. The pathological properties of these proteins lie in their three-dimensional configuration and ability to recruit and influence normal PrPs to undergo similar conformational changes. In the inherited forms of the disease, coding mutations in the PrP gene are thought to be responsible for the production of $\mathrm{PrP}^{\mathrm{Sc}}$. The two best studied forms of familial CJD are associated with a mutation at codon 200 of the PrP gene $(24,25)$. Presentation of sporadic CJD is partially determined by polymorphism at codon 129 of the PrP gene.

The transmissibility of CJD has been verified with reports of iatrogenic transmission from a corneal transplant, electroencephalographic depth electrodes, neurosurgical instruments, cadaveric dura mater grafts and human pituitary hormone administration (11-17), as well as verified in laboratory studies (26-28). Intracerebral inoculation has been found to be the most efficient means of transmission, but oral ingestion and peripheral injection have also been documented as means of transmission (26-28). Tissues reported to be infective include the central nervous system, gut, lymphatic system and muscle. Although CJD transmission through blood has been documented in the laboratory, no cases of transfusion-related CJD have been confirmed in humans yet. Transmission studies have suggested there is a relative species barrier for different TSEs (29). However, events in the United Kingdom with respect to the occurrence of variant CJD (1) and reports of CJD in 
British cattle farmers (30-32) against a backdrop of a 20-year outbreak of BSE in the cattle population raise very significant concerns about BSE being transmitted to humans.

Recent studies have provided more direct evidence to support this epidemiological association. Feeding experiments in sheep have demonstrated transmissibility of BSE via the oral route substantiating the hypothesis that the use of contaminated beef and sheep by-products in feed given to cattle in the 1970s and 1980s contributed to the BSE outbreak (33). A

\section{REFERENCES}

1. Will RG, Ironside JW, Zeidler M, et al. A new variant of Creutzfeldt-Jakob disease in the UK. Lancet 1996;347:921-5.

2. DeArmond SJ, Prusiner SB. Etiology and pathogenesis of prion diseases. Am J Pathol 1995;146:785-811.

3. Budka H, Aguzzi A, Brown P, et al. Neuropathalogical diagnostic criteria for Creutzfeld-Jakob disease and other human spongiform encephalopathies (prion diseases). Brain Pathol 1995;5:459-66.

4. Brown P. Transmissible human spongiform encephalopathy (infectious cerebral amyloidosis): Creutzfeldt-Jakob disease, Gerstmann-Sträussler-Scheinker syndrome, and kuru. In: Calne DB, ed. Neurodegenerative Diseases. Toronto: WB Saunders and Company, 1994.

5. Gajdusek DC. Unconventional viruses and the origin and disappearance of kuru. Science 1977;197:943-60.

6. Medori R, Tritschler HJ, Leblanc A, et al. Fatal familial insomnia, a prion disease with a mutation at codon 178 of the prion protein gene. N Engl J Med 1992;326:444-9.

7. Summers BA, Cummings JF, de Lahunta A. Veterinary Neuropathology. St Louis: Mosby-Year Book Inc, 1995.

8. Wells GAH, Scott AC, Johnson CT, et al. A novel progressive spongiform encephalopathy in cattle. Vet Rec 1987;121:419-20.

9. Masters CL, Harris JO, Gajdusek DC, Gibbs CJJ, Bernoulli C, Asher DM. Creutzfeldt-Jakob disease: Patterns of worldwide occurrence and the significance of familial and sporadic clustering. Ann Neurol 1979;5:177-88.

10. Will RG. Epidemiology of Creutzfeldt-Jakob disease. Br Med Bull 1993;49:960-70.

11. Brown P, Preece MA, Will RG. Friendly fire in medicine: Hormones, homografts, and Creutzfeldt-Jakob disease. Lancet 1992;340:24-7.

12. Fradkin JE, Schonberger LE, Mills JL, et al. Creutzfeldt-Jakob disease in pituitary growth hormone recipients in the United States. JAMA 1991;265:880-4.

13. Cochius JI, Burns RJ, Blumbergs PC, Mack K, Alderman CP. Creutzfeldt-Jakob disease in a recipient of human pituitary-derived gonadotrophin. Aust NZ J Med 1990;20:592-3.

14. Bernoulli C, Siegfried J, Baumgartner G, et al. Danger of accidental person-to-person transmission of Creutzfeldt-Jakob disease by surgery. Lancet 1977;i:478-9.

15. Duffy P, Wolf J, Collins G, DeVoe AG, Streeten B, Cowen D. Possible person-to-person transmission of Creutzfeldt-Jakob disease. N Engl J Med 1974;290:692.

16. Thadani V, Penar PL, Partington J, et al. Creutzfeldt-Jakob disease probably acquired from a cadaveric dura mater graft. J Neurosurg 1988;69:766-9.

17. Tange RA, Troost D, Limburg M. Progressive fata dementia (Creutzfeldt-Jakob disease) in a patient who received homograft tissue for tympanic membrane closure. Eur Arch Otorhinolaryngol 1990;247:199-201.

18. Kondo K, Kuroiwa Y. A case control study of Creutzfeldt-Jakob disease: Association with physical injuries. Ann Neurol 1982;11:377-81. study by Collinge and colleagues (23) provided the first scientific link between BSE and variant CJD. They found that the physicochemical 'fingerprint' of variant CJD prions transmitted to mice matched the disease-related isoform of the PrP of BSE but differed from the disease-related isoform seen in patients with acquired or sporadic CJD (23). These latter findings and other experiments that are underway $(23,34)$ will likely provide more evidence that BSE is the etiologic agent of variant CJD in humans.

19. Bobowick AR, Brody JA, Mathews MR, Roos R, Gajdusek DC. Creutzfeldt-Jakob disease: A case-control study. Am J Epidemiol 1973;98:381-94.

20. Davanipour Z, Alter M, Sobel E, Asher DM, Gajdusek DC. A case-control study of Creutzfeldt-Jakob disease: Dietary risk factors. Am J Epidemiol 1985;122:443-51.

21. Wientjens DPWM, Davanipour Z, Hofman A, et al. Risk factors for Creutzfeldt-Jakob disease: A reanalysis of case-control studies. Neurology 1996;46:1287-91.

22. Pablos-Méndez A, Netto EM, Defendini R. Infectious prions or cytotoxic metabolites? Lancet 1993;341:159-61.

23. Collinge J, Sidle KCL, Meads J, Ironside J, Hill AF. Molecular analysis of prion strain variation and the aetiology of "new variant" CJD. Nature 1996;383:685-90.

24. Goldfarb LG, Mitrova E, Brown P, Toh BH, Gajdusek DC. Mutation in codon 200 of scrapie amyloid protein gene in two clusters of Creutzfeld-Jakob disease in Slovakia. Lancet 1990;336:514-5.

25. Hsiao K, Meiner Z, Kahana E, et al. Mutation of the prion protein in Libyan Jews with Creutzfeldt-Jakob disease. N Engl J Med 1991;324:1091-7.

26. Brown P, Gibbs CJ, Rodgers-Johnson P, et al. Human spongiform encephalopathy: The National Institutes of Health series of 300 cases of experimentally transmitted disease. Ann Neurol 1994;35:513-29.

27. Pattison IH, Millson GC. Distribution of the scrapie agent in the tissues of experimentally inoculated goats. J Comp Path 1962;72:233-44.

28. Gibbs CJ, Amyx HL, Bacote A, Masters CL, Gajdusek DC. Oral transmission of kuru, Creutzfeldt-Jakob disease, and scrapie to nonhuman primates. J Infect Dis 1980;142:205-8.

29. Carp RI, Ye X, Kascsak RJ, Rubenstein R. The nature of the scrapie agent: Biological characteristics of scrapie in different strain-host combinations. Ann NY Acad Sci 1994;724:221-34.

30. Sawcer SJ, Yuill GM, Esmonde TFG, et al. Creutzfeldt-Jakob disease in an individual occupationally exposed to BSE. Lancet 1993;341:642. (Lett)

31. Davies PTG, Jahfar S, Ferguson IT, Windi O. Creutzfeldt-Jakob disease in individuals occupationally exposed to BSE. Lancet 1993;342:680. (Lett)

32. Smith PEM, Zeidler M, Ironside JW, Estibeiro P, Moss TH. Creutzfeldt-Jakob disease in a dairy farmer. Lancet 1995;346:898. (Lett)

33. Foster JD, Bruce M, McConnell I, Chree A, Fraser H. Detection of BSE infectivity in brain and spleen of experimentally infected sheep. Vet Rec 1996;138:546-8.

34. Collinge J. New diagnostic tests for prion diseases. Comment on. N Engl J Med 1996;335:924-30; N Engl J Med 1996;335:963-5.

\author{
John M Conly MD FRCPC \\ Toronto, Ontario \\ Stephen D Shafran MD FRCPC \\ Edmonton, Alberta
}




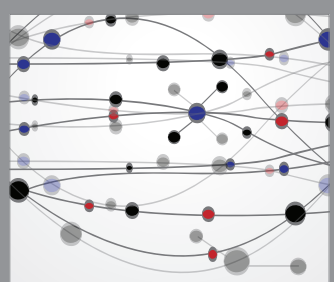

The Scientific World Journal
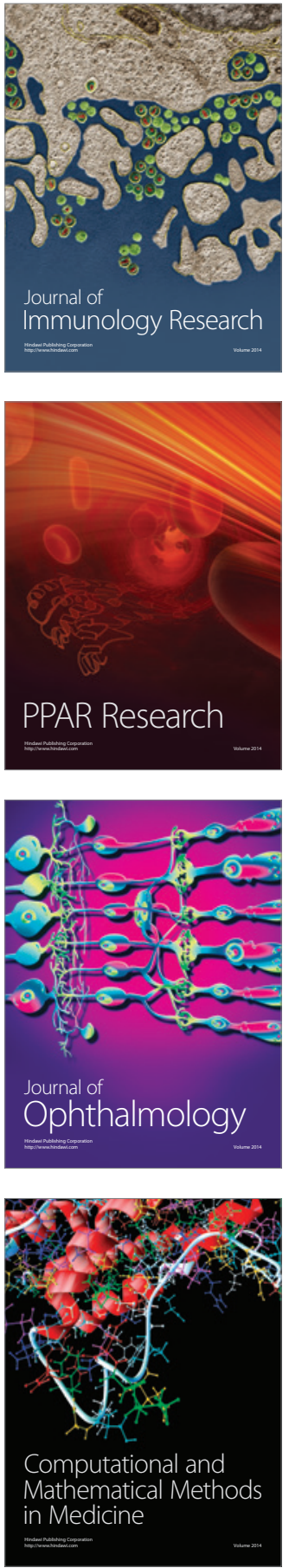

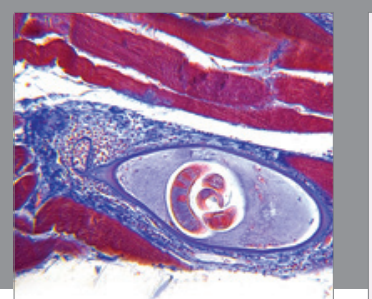

Gastroenterology Research and Practice

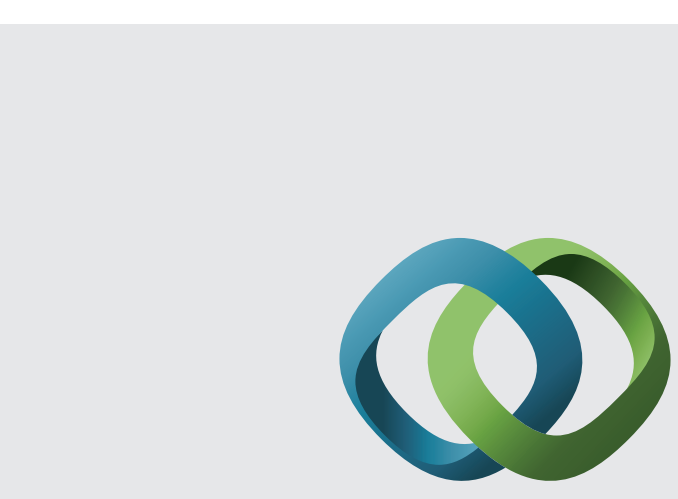

\section{Hindawi}

Submit your manuscripts at

http://www.hindawi.com
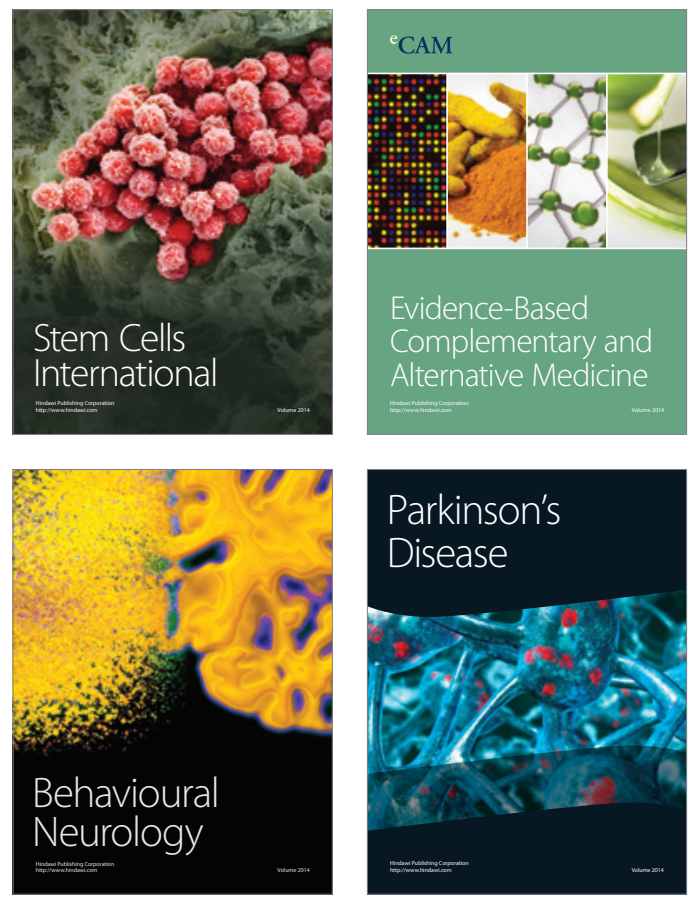
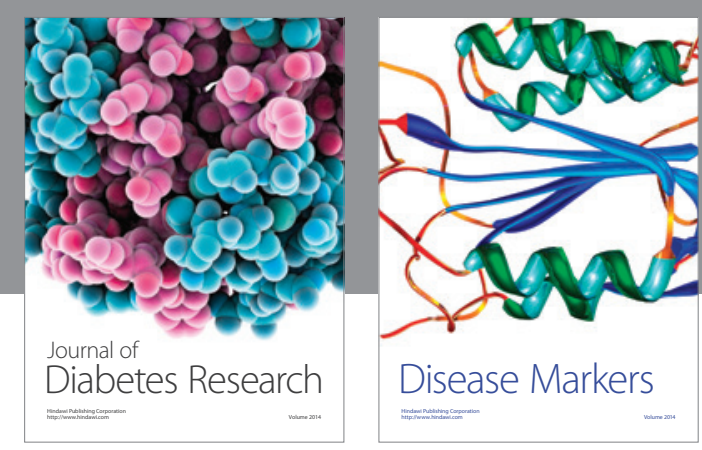

Disease Markers
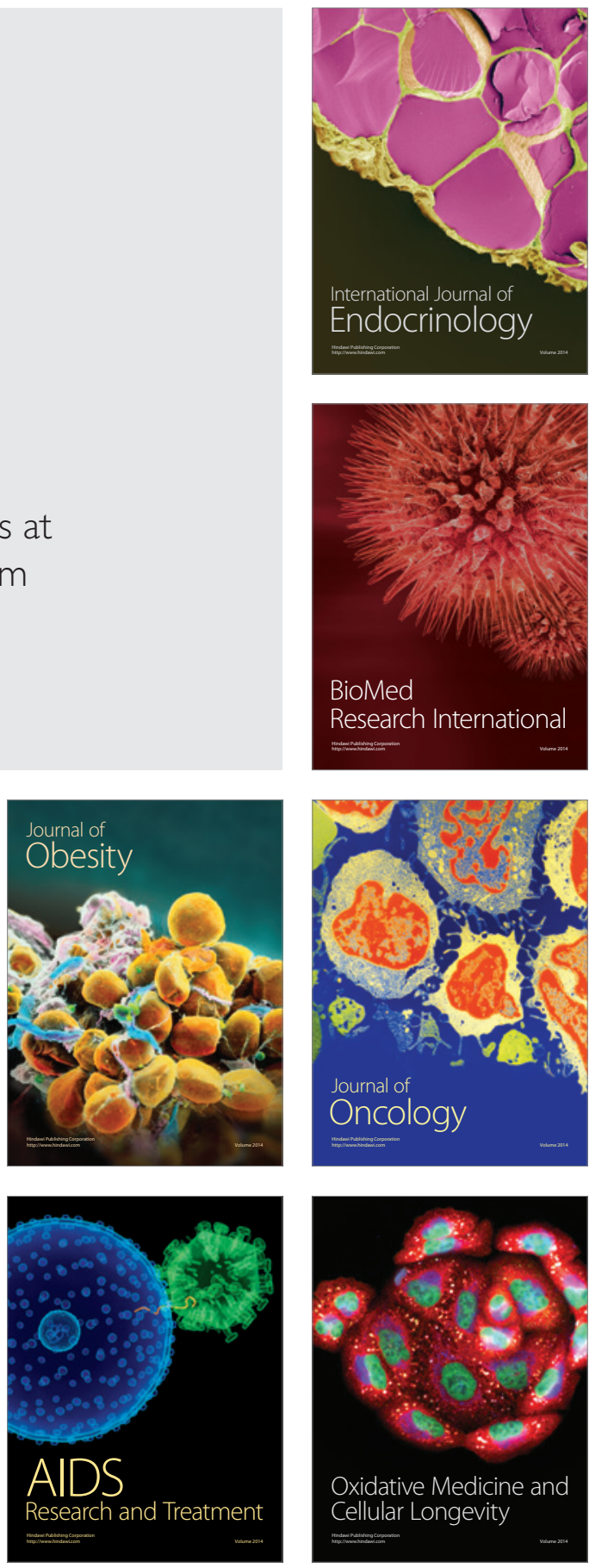